places word for word by a paper to be delivered next week in Berne by Academician G.S. Golitsyn of the Institute of Atmospheric Physics in Moscow) shows that there may be a rich vein of historical research yet to be tapped. ICSU itself might think of issuing a temporizing opinion on the matter, one that draws attention to the uncertainties running through all the arguments so far advanced to calculate the consequences of a nuclear war, to work that remains undone and, recognizing that the stated purpose of deterrence is to avoid nuclear war, urges those with good intentions to direct them at practical tasks.

\section{Academics in clover?}

\section{Harvard prompts the question whether universi- ties are being diverted from academic ways.}

HARVARD University is rightly proud of its place in modern scholarship as well as of its role in formulating and defending the concept of the autonomous university. So the element of hoopla in last week's celebration of Harvard's 350th anniversary (see page 103) is forgiveable, and was probably unavoidable. How else, for that matter, does a great institution remind itself of past achievements, and gather the resolve to make the future as bright as possible? Yet there are obvious dangers, of which outstanding institutions are well aware. Especially because the reputation of a university rests on its corporate intellectual quality, there is always a narrow gap between others' admiration and resentment. In most places, the most successful universities are regarded as bastions of privilege by academics elsewhere, just as universities as a whole may be tarred with the same brush in the more general opinion. In the United States there are now, to the common good fortune, a dozen institutions other than Harvard with comparable reputations, mostly won by quite different means.

Yet Harvard has a problem, one that must peculiarly afflict an institution whose cry has always been the primacy of scholarship and its accompaniments, teaching and research. The difficulty was well described last week by Dr Derek Bok, the university's president: inevitably, as public funds for the support of research shrink, or are spread over a growing throng of claimants, academics must turn to other sources both for funds and, ultimately, for approval. Industrial partnerships of various kinds are now the fashion. Bok might have added that, as in other ways, academics at the more successful institutions are the better able to lay claim to these alternative sources of support.

The Harvard faculty restrains its members from carrying out militarily classified research, but the restraints on commercial work are less explicit. The difficulty becomes a dilemma because, as Bok acknowledged last week, there is a case for asking that outstanding institutions and their academics can usefully contribute to wider social objectives by assisting industrial innovation. The question is where to draw the line between outside commitments which are productive and even stimulating for those concerned and commitments which are distracting and a threat to scholarship. Harvard is obviously worried that the line may already be blurred.

For what it is worth, the problem is not unique to Harvard nor intractable. The first need is that its nature, and the danger that it poses, should be recognized for what they are. The most serious danger is that too close an involvement with commercial activities is intellectually and emotionally distracting, and a thief of people's time. The extreme case is that when academics have some kind of management responsibility for extramural enterprises; then, if things go wrong, their fiducial responsibilities may require them to abandon their responsibilities to students and to research. Other dangers are more sordid, to do with the money that academics can now earn by energetic moonlighting. A particularly insidious danger is that academics might come to accept as tests of achievement standards which have nothing to do with scholarship, thereby compromising the distinctiveness of the university as an institution and the reasons for its continuing existence.

The safeguards are also obvious. What academics do extramurally should be made clear to their colleagues, whose opinions of what is permissible should carry at least as much weight as that of would-be entrepreneurs. Attempts to control the time that people spend on outside activities are inevitable but less effective than they appear; who can control what goes on inside a person's head? A better general solution would be to require that extramural workers should share their rewards with their universities, at the institutional or departmental level.

In the past few years, the Harvard faculty has dealt intelligently with a number of cases of this kind thrown up by the emergence of new techniques in biotechnology. But now the field of opportunity is widening. In the circumstances, the most urgent need is for a more explicit way of regulating these affairs. That Harvard should have been among the first publicly to acknowledge the danger is not a sign that it is far along the slippery slope, but that it still knows what universities are for. Research, of course. Teaching, more earnestly than at present, even at Harvard. But also the constructive irreverence made possible by the conjunction of courageous people and independence. Universities everywhere can boast of the first; Harvard's good fortune is that it still enjoys the second.

\section{Hijacking riposte}

\section{Another hijacked aircraft at Karachi last week suggests the need for more deliberate safeguards.}

HIJACKING aircraft is not merely criminal terrorism but an increasingly serious limitation of people's freedom to move about the surface of the Earth. With each new advance in the technology of remote (and not so remote) sensing for explosives and firearms, airlines understandably require passengers to arrive even earlier at the check-in counters, increasing the proportion of each journey which constitutes dead time while adding substantially to the total cost. Yet the security people are the first to say that they are necessarily looking, without much success to judge from the lack of prosecutions for carrying weapons onto aircraft, for needles in a haystack. So might they not think of narrowing the search, in a field in which even innocent passengers must be judged suspect until they are cleared, by eliminating a substantial number of people from scrutiny?

Here is how it might be done. Part of the airport problem is to know the identity of travellers, so why not arrange that potential passengers may, if they wish, establish their identity in advance by telling some airline computer who they are and what they do? Whether the same person later turns up at the check-in counter could then be verified by one of the devices which the banks are contemplating for telling the identity of individuals; a person might, for example, record the ages of siblings, the nick-names of schoolteachers and a host of other trivial but idiosyncratic information, all of which might be checked by a few questions at random formulated by a computer. A few seconds at an airport desk might replace the tens of minutes now spent crawling through the security checks.

Only the airlines can tell how great the saving of time and effort would be, but it cannot but be substantial. The people most likely to volunteer their identities in such a way would most probably be the frequent travellers, but they are by definition a substantial part of the airline traffic. Irregular travellers would complain of being at a disadvantage, but a suitable system could be made to work for all who volunteer. But who says that it is a fair price to pay for the abatement of hijacking that there should be a huge data-bank filled with intimate information about people at random? Properly run, a system like this should not be an offence against civil liberties: of necessity, only information so trivial that imposters would never know it would be required. 